\title{
Genome-wide association study of smoking behaviours in patients with COPD
}

\author{
Mateusz Siedlinski, ${ }^{1}$ Michael H Cho, ${ }^{1,2}$ Per Bakke, ${ }^{3}$ Amund Gulsvik, ${ }^{3}$ David A Lomas, \\ Wayne Anderson, ${ }^{5}$ Xiangyang Kong, ${ }^{6}$ Stephen I Rennard, ${ }^{7}$ Terri H Beaty, ${ }^{8}$ \\ John E Hokanson, ${ }^{9}$ James D Crapo, ${ }^{10}$ Edwin K Silverman, ${ }^{1,2}$ the COPDGene \\ Investigators and ECLIPSE Investigators
}

\begin{abstract}
- Additional materials are published online only. To view these files please visit the journal online (http://thorax.bmj. com).

For numbered affiliations see end of article.

\section{Correspondence to Edwin K Silverman, 181 Longwood Avenue, Boston, MA 02115, USA; ed.silverman@ channing.harvard.edu}

This article is based on research that is funded in part by grants from the National Institute of Health (NIH) and is therefore subject to the mandatory $\mathrm{NIH}$ Public Access Policy. The final, peer-reviewed manuscript must be deposited with the PubMed Central (PMC) database upon acceptance for publication and be made publicly accessible no later than 12 months after publication.

Received 8 March 2011 Accepted 16 May 2011 Published Online First 16 June 2011

\section{ABSTRACT}

Background Cigarette smoking is a major risk factor for chronic obstructive pulmonary disease (COPD) and COPD severity. Previous genome-wide association studies (GWAS) have identified numerous single nucleotide polymorphisms (SNPS) associated with the number of cigarettes smoked per day (CPD) and a dopamine beta-hydroxylase (DBH) locus associated with smoking cessation in multiple populations

Objective To identify SNPS associated with lifetime average and current CPD, age at smoking initiation, and smoking cessation in patients with COPD.

Methods GWAS were conducted in four independent cohorts encompassing 3441 ever-smoking patients with COPD (Global Initiative for Obstructive Lung Disease stage II or higher). Untyped SNPs were imputed using the HapMap (phase II) panel. Results from all cohorts were meta-analysed.

Results Several SNPs near the HLA region on chromosome $6 \mathrm{p} 21$ and in an intergenic region on chromosome 2q21 showed associations with age at smoking initiation, both with the lowest $p=2 \times 10^{-7}$. No SNPs were associated with lifetime average CPD, current CPD or smoking cessation with $\mathrm{p}<10^{-6}$. Nominally significant associations with candidate SNPs within cholinergic receptors, nicotinic, alpha $3 / 5$ (CHRNA3/CHRNA5; eg, $\mathrm{p}=0.00011$ for SNP rs1051730) and cytochrome P450, family 2, subfamily A, polypeptide 6 (CYP2A6; eg, $p=2.78 \times 10^{-5}$ for a non-synonymous SNP rs1801272) regions were observed for lifetime average CPD, however only CYP2A6 showed evidence of significant association with current CPD. A candidate SNP (rs3025343) in DBH was significantly $(p=0.015)$ associated with smoking cessation.

Conclusion The authors identified two candidate regions associated with age at smoking initiation in patients with COPD. Associations of CHRNA3/CHRNA5 and CYP2A6 loci with CPD and DBH with smoking cessation are also likely of importance in the smoking behaviours of patients with COPD.

\section{INTRODUCTION}

Chronic obstructive pulmonary disease (COPD) is a common, genetically complex disease caused, and accelerated in its progression, predominantly by tobacco smoking. High smoking intensity, likely related at least in part to nicotine addiction, increases the risk of developing COPD. Although many patients quit smoking after they are diagnosed with COPD, some continue to smoke,

\section{Key messages}

What is the key question?

- Identification of genetic markers associated with smoking behaviours in patients with chronic obstructive pulmonary disease (COPD).

What is the bottom line?

- This case-only genome-wide association study identifies two candidate loci for age at smoking onset.

\section{Why read on?}

- It additionally confirms associations of the CYP2A6 and $15 q 25$ loci with smoking intensity and of the $D B H$ locus with smoking cessation in patients with COPD.

placing them at high risk for continued disease progression.

Smoking behaviours, such as age at smoking initiation, smoking cessation, and number of cigarettes smoked per day (CPD), are partially genetically determined and have substantial heritability. ${ }^{1-4}$ Numerous loci and candidate genes have been suggested to contain genetic markers affecting smoking behaviours using genomewide linkage scans ${ }^{5}$ and genome-wide association study (GWAS) approaches. ${ }^{6}$ Recent GWAS have identified loci associated with smoking cessation (dopamine beta-hydroxylase $(\mathrm{DBH})$ on chromosome 9q34) and CPD (eg, cholinergic nicotinic receptors locus on chromosome $15 \mathrm{q} 25$ and cytochrome P450, family 2, subfamily A, polypeptide 6 (CYP2A6) locus on chromosome 19q13) in multiple populations, ${ }^{8-11}$ although GWAS of smoking behaviours specifically of patients with COPD have not been reported. Interestingly, the same single nucleotide polymorphisms (SNPs) in the 15q25 locus were previously associated with development of COPD, ${ }^{12}$ but the role of this locus in smoking behaviours in patients with COPD and whether the sole effect of this locus on COPD susceptibility relates to smoking behaviour remain unclear.

Because of their typically heavy lifetime smoking exposures, potentially related to (at least in part) enrichment in genetic variants responsible for nicotine addiction, patients with COPD can be considered as a unique population for studying smoking behaviours. However, diagnosis and 
further progression of COPD are likely to modify smoking status (ie, increased efforts to quit smoking) and smoking intensity (eg, reduction of $\mathrm{CPD}$ ). Identifying genetic factors involved in smoking cessation is of special importance in clinical practice, since quitting smoking may reduce subsequent loss of lung function in patients with COPD. ${ }^{13} 14$ Smoking cessation results in an improvement of respiratory symptoms in patients with COPD, and is associated with reduced mortality due to COPD. ${ }^{13-16}$ Another smoking-related phenotype, age at smoking onset, correlates with nicotine dependence in adulthood $^{17}$ and mortality due to COPD. ${ }^{15}$ Taken together, it is of special interest to search for markers associated with smoking behaviours uniquely among patients with COPD. Likewise, it is of importance to assess whether SNPs, regarded as established genetic determinants of smoking cessation and CPD in other populations, associate with these traits in patients with COPD as well. Identification and description of such genetic variations may have significant consequences on future, targeted therapy aiming to reduce smoking among patients with COPD.

The aim of the current study was to identify SNPs associated with age at smoking initiation, smoking cessation, current and lifetime average CPD among patients with COPD, using GWAS in four independent cohorts: National Emphysema Treatment Trial (NETT), Evaluation of COPD Longitudinally to Identify Predictive Surrogate End-points (ECLIPSE), GenKOLS cohort from Bergen, Norway, and COPDGene. The authors additionally hypothesised that a subset of smoking behaviour genetic determinants in other population samples would influence smoking behaviour in patients with COPD.

\section{METHODS}

\section{Subjects and phenotypes}

Ever-smoking, Caucasian patients with at least moderate COPD (Global Initiative for Obstructive Lung Disease stage II or higher) from four independent cohorts (NETT, ${ }^{18}$ ECLIPSE, ${ }^{19}$ GenKOLS cohort from Bergen, Norway, ${ }^{20}$ and COPDGene (first 1000 subjects) ${ }^{21}$ ) were studied (table 1). In total 3441 patients had at least one (out of four) non-missing, smoking-related phenotype (table 1). All phenotypes were self-reported using either a Case Report Form (smoking status and the lifetime average CPD in the ECLIPSE cohort) or modified versions of the American Thoracic Society/Division of Lung Diseases Respiratory Disease Questionnaire. ${ }^{22}$ Because current smokers were not eligible for the NETT study, this cohort did not contribute to the analyses on smoking cessation and current CPD.

\section{Genotyping and quality control}

Different genotyping chips from Illumina (San Diego, California, USA) were used (table 1). Quality control (OC) steps were previously described in detail for the NETT, Norwegian and ECLIPSE cohorts, ${ }^{23}$ and were applied to the COPDGene study as well. Briefly, OC steps consisted of filtering SNPs based on missing call rates $(>5 \%)$ and Hardy-Weinberg Equilibrium deviation $\left(\mathrm{p}<10^{-8}\right)$, and filtering patients based on genotyping call rate $(<95 \%)$, sex discrepancy, unexpected relatedness (PLINK pihat cut-off of 0.125 ), and ethnicity. Removal of cases that were outliers for genetic ancestry was performed based on principal components analysis in cases only. In the primary analysis, untyped markers were imputed using 120 founder Caucasian

Table 1 Characteristics of patients with chronic obstructive pulmonary disease (COPD) and smoking-related phenotypes studied

\begin{tabular}{|c|c|c|c|c|}
\hline & \multicolumn{4}{|l|}{ Cohort } \\
\hline & NETT $n=362 *$ & Norway $n=851 *$ & ECLIPSE $n=1734^{*}$ & COPDGene $n=494^{*}$ \\
\hline \multicolumn{5}{|l|}{ Characteristics } \\
\hline Men*, n (\%) & $234(64.6)$ & $511(60.0)$ & 1160 (66.9) & $242(49.0)$ \\
\hline Age in years*, Mean (SD) & $67.4(5.8)$ & $65.5(10.1)$ & $63.7(7.1)$ & $64.7(8.1)$ \\
\hline Pack-years smoked ${ }^{*}$, Mean (SD) & $66.1(30.9)$ & $32.1(18.6)$ & $50.4(27.4)$ & $54.8(26.8)$ \\
\hline Post-bronchodilator $\mathrm{FEV}_{1}$ (\% pred.) ${ }^{*}$, Mean (SD) & $29.1(7.8)$ & $50.7(17.5)$ & $44.8(14.7)$ & $48.7(18.4)$ \\
\hline Post-bronchodilator $\mathrm{FEV}_{1} / \mathrm{FVC}^{*}$, Mean (SD) & $0.32(0.06)$ & $0.51(0.13)$ & $0.45(0.12)$ & $0.48(0.13)$ \\
\hline Enrolment, Years & 1998-2002 & $2003-2005$ & $2005-2007$ & $2008-2009$ \\
\hline Genotyping technology, Chip & Illumina Quad 610 & $\begin{array}{l}\text { Illumina HumanHap } \\
550 \text { V1, V3, and Duo }\end{array}$ & $\begin{array}{l}\text { Illumina HumanHap } \\
550 \text { V3 }\end{array}$ & $\begin{array}{l}\text { Illumina Human } \\
\text { Omni1-Quad }\end{array}$ \\
\hline \multicolumn{5}{|l|}{ Phenotype studied } \\
\hline \multicolumn{5}{|l|}{ Age at smoking initiation } \\
\hline Mean (SD) & $16.6(3.6)$ & $18.7(5.1)$ & $16.9(4.4)$ & $16.8(4.4)$ \\
\hline Number of patients with non-missing phenotype & 362 & 851 & 1690 & 494 \\
\hline Lambda inflation factor & 0.986 & 0.989 & 1.019 & 0.997 \\
\hline \multicolumn{5}{|l|}{ Lifetime average CPD } \\
\hline Mean (SD) & $32.4(13.5)$ & $15.7(7.8)$ & $25.5(12.4)$ & $27.6(11.8)$ \\
\hline Number of patients with non-missing phenotype & 361 & 851 & 1734 & 494 \\
\hline Lambda inflation factor & 1.002 & 0.996 & 1.018 & 0.996 \\
\hline \multicolumn{5}{|l|}{ Smoking cessation } \\
\hline Current smokers, n (\%) & $0(0)$ & $404(47.5)$ & $610(35.3)$ & $150(30.6)$ \\
\hline Former smokers, $\mathrm{n}(\%)$ & $362(100)$ & $447(52.5)$ & $1120(64.7)$ & $340(69.4)$ \\
\hline Lambda inflation factor & - & 1.000 & 0.998 & 0.995 \\
\hline \multicolumn{5}{|l|}{ Current CPD† } \\
\hline Mean (SD) & - & $13.1(6.9)$ & $15.6(10.8)$ & $18.4(12.4)$ \\
\hline Number of patients with non-missing phenotype & - & 398 & 565 & 150 \\
\hline Lambda inflation factor & - & 0.995 & 1.005 & 0.997 \\
\hline
\end{tabular}

*Calculated for patients with at least one non-missing phenotype.

tFor patients with reported current $\mathrm{CPD}>0$.

CPD, number of cigarettes smoked per day; ECLIPSE, Evaluation of COPD Longitudinally to Identify Predictive Surrogate End-points; FEV ${ }_{1}$, forced expiratory volume in 1 s; FVC, forced vital capacity; NETT, National Emphysema Treatment Trial. 
(Centre d'Etude du Polymorphisme Humain (Utah residents with ancestry from northern and western Europe) (CEU)) haplotypes from HapMap reference panel (phase II) and, as a secondary analysis, using 1000 Genomes Project data. ${ }^{24}{ }^{25} \mathrm{We}$ limited our analysis to SNPs genotyped/imputed in at least two cohorts, with imputation $r^{2}$ coefficient $\geq 0.3$ (for imputed SNPs only). Overall, approximately 2.5 and 6.3 million SNPs per phenotype were analysed using the reference HapMap Project and 1000 Genomes Project panels, respectively.

\section{Association analysis of candidate SNPs}

We extracted candidate SNPs achieving genome-wide significance in the previous studies on smoking cessation and $\mathrm{CPD}^{8-11}{ }^{26}$ Following previous GWAS, ${ }^{8} 9$ we additionally extracted two SNPs from CYP2A6 (rs1801272 (Leu160His)) and cholinergic receptor, nicotinic, alpha 5 (CHRNA5, rs588765) based on their biological function. Since a candidate SNP from the $D B H$ locus and most of the candidate SNPs from the CYP2A6 locus were imputed in all cohorts, we searched for the best proxy SNP genotyped in at least three of the cohorts.

\section{Statistics}

According to Box-Cox transformation ${ }^{27}$ that identified approximately the best transformation of dependent variables, which could be applied to all cohorts, we studied $\log _{2}$-transformed age at smoking initiation and lifetime average $\mathrm{CPD}$, and the square root of the current CPD. Regression models were run under an additive model for SNPs, while adjusting for potential confounders (see online supplementary material for details). A fixed effect model was used for all meta-analyses. Effect allele was defined as the one associated with later age at smoking initiation, higher CPD or higher odds for smoking cessation. Meta-analytic $\mathrm{p}<5 \times 10^{-8}$ was considered as genome-wide significant $^{28} ; 5 \times 10^{-8} \leq \mathrm{p}<5 \times 10^{-7}$ was interpreted as a suggestive association in the genome-wide panel with $p<0.05$ as a suggestive association for candidate SNPs.

\section{Software}

Box-Cox transformations were performed with MASS package, ${ }^{27}$ while lambda inflation factors were calculated with GenABEL package ${ }^{29}$ in R (V.2.10.1). ${ }^{30}$ SNP imputation was performed with MACH (V.1.0). ${ }^{31}$ Principal components, reflecting genetic structure of each study population, were calculated and analysed with the EIGENSOFT package (V.2.0). ${ }^{32}$ Genetic association analyses and meta-analyses were run with PLINK (V.1.0.7). ${ }^{33} 34$ SNAP (V.2.2) ${ }^{35}$ was used to search for proxy SNPs $\left(r^{2} \geq 0.8\right)$ using the CEU HapMap phase II panel and to assess linkage disequilibrium (LD) coefficients in 1000 Genomes Project data. SNP/gene annotations and regional association plots were created with LocusZoom (V.1.1; human genome build hg18). ${ }^{36}$

\section{RESULTS}

\section{Age at smoking initiation}

Analyses in the individual cohorts were adjusted for sex and principal components for genetic ancestry. In total, the metaanalysis included 3397 patients for the age at smoking initiation phenotype. Lambda inflation factors were between 0.986 and 1.019 for individual cohorts (table 1), and 1.002 for metaanalytic $p$ values (see online figure $S 1$ for a $Q-Q$ plot of metaanalysis). No SNPs showed meta-analytic association $\mathrm{p}$ values below the genome-wide significance level. Numerous SNPs in the intergenic region on chromosome $2 \mathrm{q} 21$ and in the region between BCL2-antagonist/killer 1 (BAK1) and zinc finger and
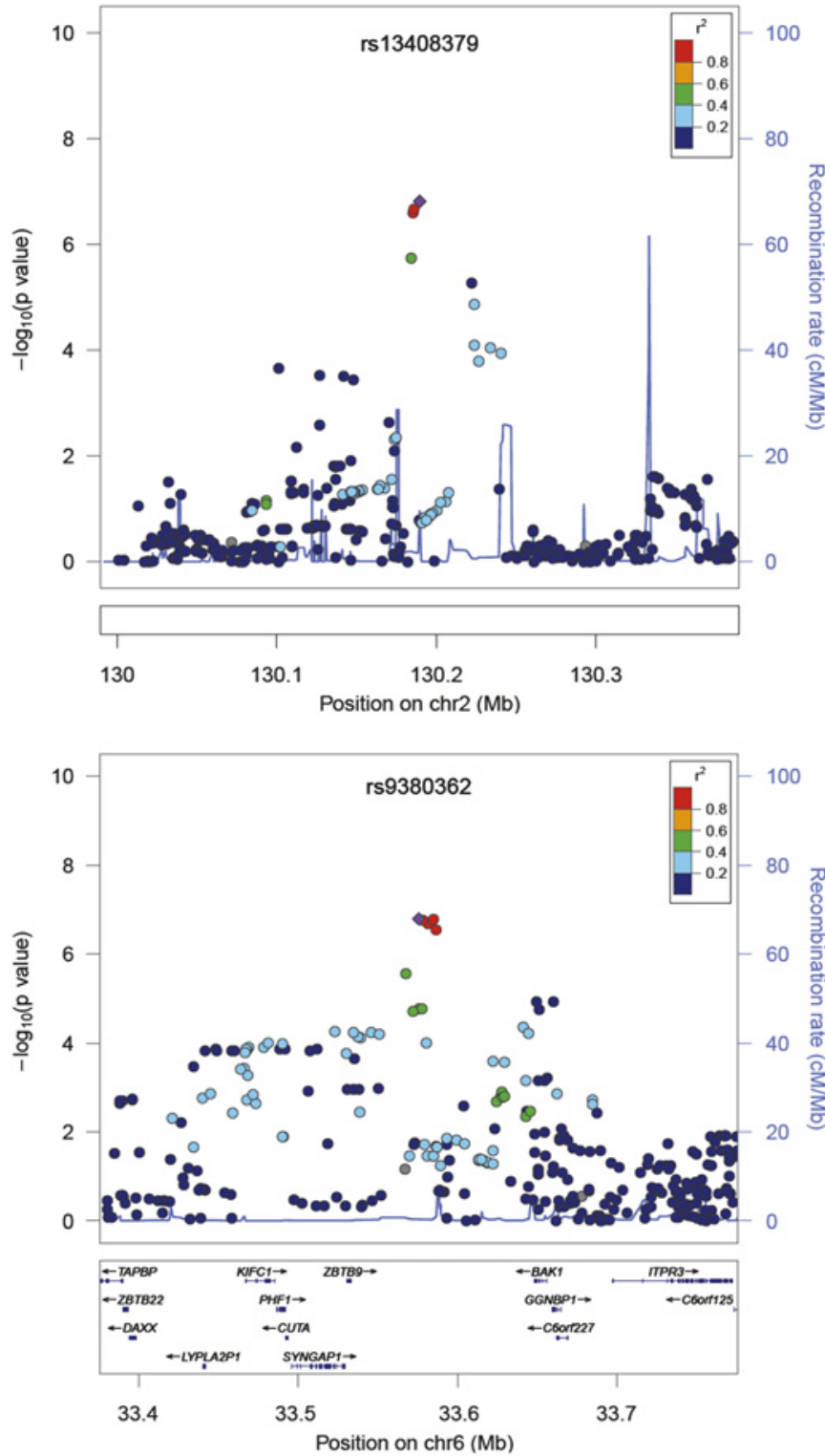

Figure 1 Regional association plots of two loci including single nucleotide polymorphisms (SNPs) associated with age at smoking initiation with meta-analytic $p<10^{-6}$. Dots correspond to meta-analysed SNPs. Colour of dots corresponds to $\mathrm{r}^{2}$ (linkage disequilibrium (LD) coefficient in the HapMap II CEU population; grey dots correspond to SNPs with missing LD information) relative to the most significantly associated SNP (depicted with diamond) in the region that is, rs13408379 (top figure) and rs9380362 (bottom figure).

BTB domain containing 9 (ZBTB9) on chromosome 6p21 were associated with age at smoking initiation at a suggestive significance level (figure 1 and online table S1). In total, 24 SNPs were associated with age at smoking initiation with $\mathrm{p}<10^{-5}$ in the meta-analysis (see online table S1).

\section{Lifetime average CPD}

Analyses in single cohorts were adjusted for sex, age and principal components for genetic ancestry. In total, the meta-analysis included 3440 patients for the lifetime average CPD phenotype. Lambda inflation factors were between 0.996 and 1.018 for individual cohorts (table 1), and 1.019 for metaanalytic $p$ values (see online figure $S 2$ for a $Q-Q$ plot of metaanalysis). Thirteen SNPs were associated with lifetime average 
Table 2 Single nucleotide polymorphisms (SNPs) associated with the lifetime average number of cigarettes smoked per day (CPD) ( $\log _{2}$-transformed) with meta-analytic $\mathrm{p}<10^{-5}$, and candidate SNPs from CHRNA3/CHRNA5 and CYP2A6 loci identified by previous studies

\begin{tabular}{|c|c|c|c|c|c|c|c|c|c|c|c|}
\hline & Chr. & Top SNP & $\begin{array}{l}\text { Nearest gene within } \\
\mathbf{5 0 ~ k b ~ ( l o c a t i o n ) ~}\end{array}$ & $\begin{array}{l}\text { Effect// } \\
\text { non-effect } \\
\text { allele }\end{array}$ & B & $\mathbf{p}$ & $I^{2}$ & O stat. & $\mathbf{N} / \mathbf{N}_{\text {imp }}$ & Freq. & $\begin{array}{l}\text { Effect direction } \\
\text { consistent with } \\
\text { previous studies }\end{array}$ \\
\hline \multirow[t]{13}{*}{ Top SNPs } & 4 & rs13104971 & SCFD2 (intron) & $G / A$ & 0.113 & $1.18 \times 10^{-6}$ & 0 & 0.92 & $4 / 3$ & 0.13 & - \\
\hline & 9 & rs 943306 & ASTN2 (intron) & $\mathrm{T} / \mathrm{C}$ & 0.073 & $1.25 \times 10^{-6}$ & 25 & 0.26 & $4 / 0$ & 0.40 & - \\
\hline & 7 & rs10237067 & - & $\mathrm{A} / \mathrm{G}$ & 0.072 & $2.98 \times 10^{-6}$ & 0 & 0.63 & $4 / 3$ & 0.63 & - \\
\hline & 7 & rs 12699125 & CALN1 (intron) & $\mathrm{A} / \mathrm{G}$ & 0.072 & $3.17 \times 10^{-6}$ & 42 & 0.16 & $4 / 3$ & 0.66 & - \\
\hline & 7 & rs4718827 & - & $\mathrm{T} / \mathrm{C}$ & 0.072 & $3.36 \times 10^{-6}$ & 0 & 0.61 & $4 / 4$ & 0.63 & - \\
\hline & 7 & rs 4717631 & CALN1 (intron) & $\mathrm{A} / \mathrm{G}$ & 0.072 & $3.60 \times 10^{-6}$ & 43 & 0.15 & $4 / 4$ & 0.66 & - \\
\hline & 7 & rs17170849 & ELMO1 (intron) & $\mathrm{C} / \mathrm{T}$ & 0.265 & $4.07 \times 10^{-6}$ & 44 & 0.15 & $4 / 3$ & 0.02 & - \\
\hline & 7 & rs 4577845 & CALN1 (intron) & $G / A$ & 0.071 & $4.57 \times 10^{-6}$ & 44 & 0.15 & $4 / 1$ & 0.66 & - \\
\hline & 7 & rs1859485 & CALN1 (intron) & $\mathrm{T} / \mathrm{C}$ & 0.069 & $6.95 \times 10^{-6}$ & 40 & 0.17 & $4 / 1$ & 0.65 & - \\
\hline & 12 & rs11044734 & - & $\mathrm{G} / \mathrm{C}$ & 0.112 & $7.32 \times 10^{-6}$ & 0 & 0.48 & $4 / 4$ & 0.90 & - \\
\hline & 12 & rs11044737 & - & $\mathrm{G} / \mathrm{A}$ & 0.112 & $7.70 \times 10^{-6}$ & 0 & 0.47 & $4 / 0$ & 0.90 & - \\
\hline & 16 & rs190369 & - & $\mathrm{C} / \mathrm{T}$ & 0.161 & $8.89 \times 10^{-6}$ & 47 & 0.13 & $4 / 1$ & 0.05 & - \\
\hline & 20 & rs2869961 & CEBPB (5' region) & $A / G$ & 0.104 & $9.65 \times 10^{-6}$ & 0 & 0.59 & $4 / 1$ & 0.12 & - \\
\hline \multirow[t]{13}{*}{ Candidate SNPs } & 15 & rs 1051730 & CHRNA3 (exon, Tyr215Tyr) & $\mathrm{A} / \mathrm{G}$ & 0.060 & 0.00011 & 37 & 0.19 & $4 / 0$ & 0.41 & Yes \\
\hline & 15 & rs 16969968 & CHRNA5 (exon, Asp398Asn) & $\mathrm{A} / \mathrm{G}$ & 0.059 & 0.00015 & 30 & 0.23 & $4 / 3$ & 0.41 & Yes \\
\hline & 15 & rs8034191 & $A G P H D 1$ (intron) & $\mathrm{C} / \mathrm{T}$ & 0.055 & 0.00036 & 40 & 0.17 & $4 / 0$ & 0.41 & Yes \\
\hline & 15 & rs 684513 & CHRNA5 (intron) & $\mathrm{C} / \mathrm{G}$ & 0.029 & 0.163 & 0 & 0.98 & $4 / 4$ & 0.80 & Yes \\
\hline & 15 & rs578776 & CHRNA3 (3' UTR) & $G / A$ & 0.041 & 0.020 & 0 & 0.94 & $4 / 0$ & 0.76 & Yes \\
\hline & 15 & rs588765 & CHRNA5 (intron) & $\mathrm{C} / \mathrm{T}$ & 0.031 & 0.046 & 47 & 0.13 & $4 / 4$ & 0.60 & Yes \\
\hline & 19 & rs3733829 & EGLN2 (intron) & $G / A$ & 0.019 & 0.223 & 0 & 0.48 & $4 / 3$ & 0.39 & Yes \\
\hline & 19 & rs7937 & $R A B 4 B$ (3' UTR) & $\mathrm{T} / \mathrm{C}$ & 0.022 & 0.153 & 0 & 0.96 & $4 / 0$ & 0.60 & Yes \\
\hline & 19 & rs1801272 & CYP2A6 (exon, Leu160His) & $\mathrm{A} / \mathrm{T}$ & 0.266 & $2.78 \times 10^{-5}$ & 0 & 0.72 & $4 / 4$ & 0.96 & Yes \\
\hline & 19 & rs4105144 & CYP2A6 (5' region) & $\mathrm{C} / \mathrm{T}$ & 0.073 & $3.92 \times 10^{-5}$ & 0 & 0.44 & $4 / 4$ & 0.73 & Yes \\
\hline & 19 & rs7260329 & CYP2B6 (intron) & $G / A$ & 0.014 & 0.404 & 0 & 0.55 & $4 / 1$ & 0.68 & Yes \\
\hline & 19 & rs7251570 & CYP2A6 (3' region) & $\mathrm{G} / \mathrm{A}$ & 0.057 & 0.00073 & 0 & 0.84 & $4 / 4$ & 0.71 & Yes \\
\hline & 19 & rs 12461383 & CYP2A7 (3' region) & $\mathrm{G} / \mathrm{C}$ & 0.063 & 0.00019 & 0 & 0.61 & $4 / 4$ & 0.60 & Yes \\
\hline
\end{tabular}

Analyses were adjusted for sex, age and principal components for genetic ancestry.

$P$ values $<0.05$ are depicted in bold.

$\mathrm{N} / \mathrm{N}_{\text {imp }}$, number of studies contributing to the meta-analysis/number of studies in which SNP was imputed; $I^{2}$, heterogeneity index; 0 stat., $p$ value for 0 statistic; $p$, $p$ value from the fixed effect meta-analysis; Freq., effect allele frequency in 3441 patients with at least one non-missing phenotype from four cohorts studied; Chr., chromosome; $B$, regression coefficient; UTR, untranslated region; CHRNA3/CHRNA5, cholinergic receptors, nicotinic, alpha 3/5; CYP2A6, cytochrome P450, family 2, subfamily A, polypeptide 6 .

CPD with meta-analytic $\mathrm{p}<10^{-5}$, however, no SNPs showed association with meta-analytic $\mathrm{p}<10^{-6}$ (table 2 ).

Candidate SNPs from the cholinergic nicotinic receptors locus on chromosome 15q25 (rs578776, rs588765, rs8034191, rs1051730 and rs16969968) were significantly $(p<0.05)$ associated with lifetime average CPD with the same direction of effect as seen in previous GWAS on CPD (table 2). The synonymous rs1051730 SNP was the top associated SNP in this locus (figure 2).

Four candidate SNPs (rs7251570, rs4105144, rs1801272 and rs12461383) in the CYP2A6 locus on chromosome 19q13 were significantly $(p<0.05)$ associated with lifetime average CPD with the same direction of effect as seen in previous GWAS on CPD (table 2). A non-synonymous SNP (rs1801272) was the second most significantly associated SNP in this locus (figure 2; table 2). There is, at most, a moderate level of LD between these four SNPs according to the HapMap phase II panel $\left(r^{2} \leq 0.6\right.$ and $D^{\prime} \geq 0.84$; see online figure S3). Analysis of proxy SNPs that were genotyped in at least three cohorts was performed. Analysis of rs8102683 (genotyped in the NETT, ECLIPSE and Norwegian cohorts, and imputed in COPDGene) that is a proxy for rs4105144 $\left(\mathrm{r}^{2}=0.87\right)$, and $\mathrm{rs} 7251418$ (genotyped in all cohorts) that is a proxy for $r s 7251570\left(r^{2}=0.81\right)$ confirmed the associations observed $\left(p=4.65 \times 10^{-5}(B=0.074\right.$ for the ' $C$ ' effect allele; $\left.\mathrm{I}^{2}=0\right)$ and $\mathrm{p}=0.0024\left(\mathrm{~B}=0.054\right.$ for the ' $\mathrm{G}$ ' effect allele; $\left.\mathrm{I}^{2}=0\right)$, respectively). No genotyped proxy SNPs could be found for rs12461383 and rs1801272 SNPs. We did not replicate, with a nominal $p<0.05$, associations between SNPs in 7p14, 8p11 and 10 q23 loci, reported in previous GWAS on CPD in our analysis on lifetime average CPD (see online table S2).

\section{Smoking cessation}

Analyses in single cohorts were adjusted for age, percentage of predicted forced expiratory volume in $1 \mathrm{~s}\left(\mathrm{FEV}_{1}\right)$ and principal components summarising genetic ancestry. In total, the metaanalysis included 1164 patients who were current smokers (defined as 'no' for smoking cessation) and 1907 patients who were former smokers (defined as 'yes' for smoking cessation). Lambda inflation factors were between 0.995 and 1.000 for individual cohorts (table 1), and 0.998 for meta-analytic $p$ values (see online figure S4 for a $\mathrm{Q}-\mathrm{Q}$ plot of meta-analysis). No SNPs showed an association with meta-analytic $\mathrm{p}<10^{-6}$ (table 3). Candidate SNP rs3025343 in the DBH locus showed nominally significant association with smoking cessation with the same direction of effect as seen in recent GWAS, yet with substantial heterogeneity between studies (table 3). SNP rs3025316, a proxy for rs3025343 $\left(r^{2}=0.94\right)$, was genotyped in all cohorts and confirmed this association ( $\mathrm{p}=0.002, \mathrm{OR}=1.32$ for the ' $\mathrm{T}$ ' effect allele; $\mathrm{I}^{2}=18$ ).

\section{Current CPD}

Analyses were adjusted for sex, age, percentage of predicted $\mathrm{FEV}_{1}$, and principal components for genetic ancestry. In total, the meta-analysis included 1113 patients who were current smokers for the current CPD phenotype. Lambda inflation factors were between 0.995 and 1.005 for individual cohorts (table 1), and 1.010 for meta-analytic $p$ values (see online figure S5 for a $\mathrm{Q}-\mathrm{Q}$ plot of meta-analysis). No SNPs showed a metaanalytic association with $\mathrm{p}<10^{-6}$ (table 4). Among candidate SNPs, rs12461383 from the CYP2A6 locus was significantly 

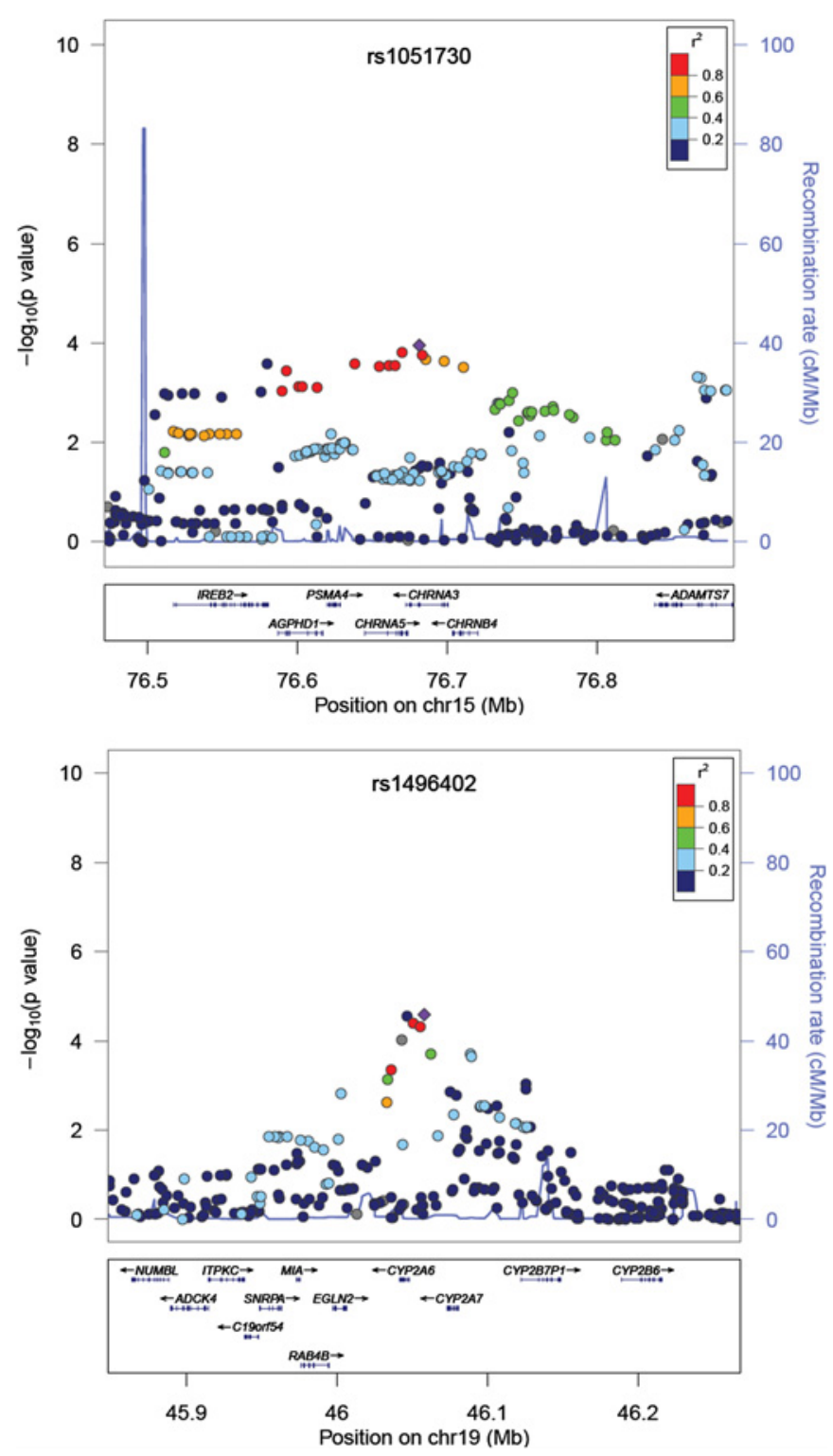

Figure 2 Regional association plots of the candidate loci centered on CHRNA3 (top) and CYP2A6 (bottom) and their associations with lifetime average number of cigarettes smoked per day. Dots correspond to metaanalysed SNPs. Colour of dots corresponds to $r^{2}$ (linkage disequilibrium (LD) coefficient in the HapMap II CEU population; grey dots correspond to SNPs with missing LD information) relative to the most significantly associated SNP in the region (depicted with diamond) that is, rs 1051730 in the CHRNA3 (top figure) and rs1496402 (bottom figure; the second top SNP in this region is a non-synonymous (Leu160His) rs1801272 SNP in the CYP2A6). Chr, chromosome; CHRNA3, cholinergic receptor, nicotinic, alpha 3; CYP2A6, cytochrome P450, family 2, subfamily A, polypeptide 6 .

associated with current CPD with the same effect direction compared with previous GWAS on CPD (table 4). Candidate SNPs rs1801272 and rs7251570 showed a borderline significant association with the same effect direction compared with previous GWAS on CPD (table 4). We did not replicate, at a nominal $\mathrm{p}<0.05$, associations between SNPs in 7p14, $8 \mathrm{p} 11$ and 10q23 loci reported in previous GWAS on CPD in our analysis on current CPD (online table S3).

\section{Analyses of SNPs imputed with $\mathbf{1 0 0 0}$ Genomes Project data}

Analysis of all phenotypes using SNP genotypes imputed using the 1000 Genomes Project revealed 20 additional associations below the suggestive genome-wide significance level (see online table S4). SNP rs9394152 in the 6p21 locus was the most significantly associated SNP with the age at smoking initiation (meta-analytic $\mathrm{p}=6.55 \times 10^{-8}$ ) and, similarly to the majority of SNPs associated with this phenotype below the suggestive genome-wide significance level, was characterised by high $(\geq 0.96)$, cohort-specific imputation $r^{2}$ coefficients (see online table S4). We observed novel associations of three SNPs with the lifetime average CPD; the most significantly associated SNP rs $28675338\left(\mathrm{r}^{2}=0.07\right.$ and $\mathrm{D}^{\prime}=1.00$ to $\mathrm{rs} 1051730$ according to 1000 Genomes Project Data) maps to the 15q25 locus. We also found one SNP associated with smoking cessation, with metaanalytic $p<5 \times 10^{-7}$ (see online table S4). Because cohort-specific, imputation $\mathrm{r}^{2}$ coefficients of the four SNPs, associated with lifetime average CPD and smoking cessation below the suggestive genome-wide significance level, were rather modest (range 0.35-0.64; see online table S4), the observed associations certainly require additional confirmation and should be interpreted with caution. The three SNPs associated with current CPD with meta-analytic $p<5 \times 10^{-7}$ map to regions on chromosomes two and three (see online table S4), which were already ranked as top loci using the HapMap II reference panel (table 4).

\section{DISCUSSION}

Cigarette smoking is the most important environmental risk factor for COPD, and smoking cessation is the most important therapeutic intervention to prevent its progression. Our current study identified two loci on chromosomes 2q21 and 6p21 as candidates for containing genes influencing age at smoking initiation in patients with COPD, both showing suggestive levels of genome-wide significance. Furthermore, this study confirmed that certain SNPs in the cholinergic nicotinic receptors locus on chromosome 15q25 and SNPs in the CYP2A6 locus on chromosome 19q13 were associated with CPD in patients with COPD. Of importance, we additionally confirmed in patients with COPD the previously reported association of a marker (rs3025343) in the DBH locus with smoking cessation.

The two loci mapping to chromosomes 2q21 and 6p21showed evidence of association with age at smoking initiation at a suggestive genome-wide significance level, using both HapMap II and 1000 Genomes projects reference imputation panels. The association peaks found here do not localise within any known genes, suggesting that distant regulation of yet unidentified target genes may be involved. SNPs from chromosome $6 \mathrm{p} 21$ are located close to the human leukocyte antigen locus, and ZBTB9 and $B A K 1$ are the closest genes to the association peak. The $B A K 1$ gene, encoding a proapoptotic protein, has been previously associated by GWAS with testicular germ cell tumours ${ }^{37}$ and platelet number. ${ }^{38}$ Yet SNPs identified in these studies do not correlate, in terms of LD, with top SNPs from our age at smoking initiation GWAS.

Analysis of candidate SNPs, with respect to the lifetime average $\mathrm{CPD}$, revealed that the majority of those SNPs in the CHRNA3/CHRNA5 (15q25) and CYP2A6 (19q13) regions significantly associated with this trait showed the same direction of effect described previously. ${ }^{8-11}{ }^{26}$ However, SNPs from the 7p14, 8p11 (CHRNB3/CHRNA6 locus) and 10q23, as well as some SNPs from the CYP2A6 and CHRNA3/CHRNAS loci, were not replicated in the current study with a nominal significance threshold. This may be caused by effect sizes that are too small to be detected in our populations or potentially to different genetic determinants of smoking behaviours within patients with COPD 
Table 3 Single nucleotide polymorphisms (SNPs) associated with smoking cessation with meta-analytic $p<10^{-5}$, and a candidate SNP (last row) from the dopamine beta-hydroxylase (DBH) locus identified by previous genome-wide association studies (GWAS) on smoking cessation

\begin{tabular}{|c|c|c|c|c|c|c|c|c|c|c|}
\hline Chr. & Top SNP & $\begin{array}{l}\text { Nearest gene } \\
\text { within } 50 \text { kb }\end{array}$ & $\begin{array}{l}\text { Effect/ } \\
\text { non-effect } \\
\text { allele } \\
\end{array}$ & $\mathbf{O R}$ & $\mathbf{p}$ & $\mathrm{I}^{2}$ & $\mathbf{0}$ stat. & $\mathrm{N} / \mathrm{N}_{\mathrm{imp}}$ & Freq. & $\begin{array}{l}\text { Effect direction } \\
\text { consistent with } \\
\text { previous GWAS }\end{array}$ \\
\hline 10 & rs10794613 & FLJ46361 (5' region) & $\mathrm{G} / \mathrm{C}$ & 1.43 & $3.41 \times 10^{-6}$ & 0 & 0.51 & $3 / 3$ & 0.21 & - \\
\hline 3 & rs13064954 & CCNL1 (3' region) & $A / G$ & 1.94 & $5.28 \times 10^{-6}$ & 0 & 0.60 & $3 / 2$ & 0.05 & - \\
\hline 10 & rs1896376 & CPMX2 (intron) & $\mathrm{C} / \mathrm{T}$ & 1.83 & $5.71 \times 10^{-6}$ & 57 & 0.10 & $3 / 2$ & 0.95 & - \\
\hline 13 & rs9506942 & - & $\mathrm{C} / \mathrm{G}$ & 1.29 & $5.96 \times 10^{-6}$ & 0 & 0.72 & $3 / 3$ & 0.57 & - \\
\hline 13 & rs9552733 & - & $\mathrm{G} / \mathrm{A}$ & 1.29 & $5.99 \times 10^{-6}$ & 0 & 0.69 & $3 / 0$ & 0.57 & - \\
\hline 3 & rs9866141 & VEPH1 (3' region) & $\mathrm{T} / \mathrm{C}$ & 1.88 & $7.99 \times 10^{-6}$ & 0 & 0.66 & $3 / 3$ & 0.06 & - \\
\hline 3 & rs1165640 & - & $\mathrm{C} / \mathrm{T}$ & 1.56 & $8.98 \times 10^{-6}$ & 0 & 0.57 & $3 / 0$ & 0.10 & - \\
\hline 12 & rs10861185 & TXNRD1 (intron) & $\mathrm{C} / \mathrm{A}$ & 1.29 & $9.57 \times 10^{-6}$ & 16 & 0.31 & $3 / 2$ & 0.57 & - \\
\hline 10 & rs727417 & СРXM2 (intron) & $\mathrm{C} / \mathrm{G}$ & 1.71 & $9.67 \times 10^{-6}$ & 38 & 0.20 & $3 / 3$ & 0.94 & - \\
\hline 9 & rs3025343 & $D B H$ (5' region) & $\mathrm{G} / \mathrm{A}$ & 1.24 & 0.015 & 46 & 0.16 & $3 / 3$ & 0.87 & Yes \\
\hline
\end{tabular}

Analyses were adjusted for age, \% of predicted forced expiratory volume in $1 \mathrm{~s}\left(\mathrm{FEV}_{1}\right)$ and principal components for genetic ancestry. Patients who were current smokers were considered as 'controls', while patients who were former smokers were considered as 'cases'.

$P$ values $<0.05$ are depicted in bold.

$\mathrm{N} / \mathrm{N}_{\text {imp, }}$ number of studies contributing to the meta-analysis/number of studies in which SNP was imputed; $I^{2}$, heterogeneity index; 0 stat., $p$ value for 0 statistic; $p, p$ value from the fixed effect meta-analysis; Freq., effect allele frequency in 3441 patients with at least one non-missing phenotype from four cohorts studied; Chr., chromosome.

Besides the 'neutral' or reference haplotype, it has been suggested there are at least two other haplotypes with independent effects on CPD in this 15 q25 region. ${ }^{26} 39$ Our study confirms previous observations that rs1051730, and tagging SNPs such as rs16969968, exhibit relatively strong effects in this region, and SNPs rs588765 and rs578776, determine independent haplotypes associated with lifetime CPD in patients with COPD as well. However, we could not replicate the association between lifetime average CPD and rs684513, that is, the top SNP in the analysis on CPD when conditioning for rs1051730 in the Tobacco Genetics Consortium. ${ }^{10}$ Importantly, the effect directions of all candidate SNPs in this 15q25 locus agree with those previously reported, suggesting larger COPD cohorts are required to establish significance of independent SNPs/ haplotypes in this region.

Interestingly, effect sizes of replicated SNPs from the CHRNA3/CHRNA5 locus are similar to most of those from the CYP2A6 locus in our study,which contrasts with recent GWAS where bigger effect sizes were seen for the former locus. ${ }^{8}$ Additionally, variations in the CHRNA3/CHRNA5, but not CYP2A6, locus showed substantial heterogeneity in genetic effects in our study, and as observed in previous GWAS as well. ${ }^{8} 10$ We speculate that this might be due to between-study differences in general (eg, educational status or peer smoking ${ }^{40}$ ) or

Table 4 Single nucleotide polymorphisms (SNPs) associated with the current number of cigarettes smoked per day (CPD) (square root transformed) with meta-analytic $\mathrm{p}<10^{-5}$, and candidate SNPs from CHRNA3/CHRNA5 and CYP2A6 loci identified by previous studies

\begin{tabular}{|c|c|c|c|c|c|c|c|c|c|c|c|}
\hline & Chr. & Top SNP & $\begin{array}{l}\text { Nearest gene } \\
\text { within } 50 \text { kb }\end{array}$ & $\begin{array}{l}\text { Effect/ } \\
\text { non-effect } \\
\text { allele }\end{array}$ & B & $\mathbf{p}$ & $I^{2}$ & O stat. & $\mathrm{N} / \mathrm{N}_{\mathrm{imp}}$ & Freq. & $\begin{array}{l}\text { Effect direction } \\
\text { consistent with } \\
\text { previous studies }\end{array}$ \\
\hline \multirow[t]{7}{*}{ Top SNPs } & 3 & rs1881681 & - & $\mathrm{C} / \mathrm{A}$ & 0.363 & $1.22 \times 10^{-6}$ & 33 & 0.22 & $3 / 0$ & 0.88 & - \\
\hline & 2 & rs 12615264 & $\operatorname{socs5}\left(3^{\prime}\right.$ region) & $\mathrm{T} / \mathrm{G}$ & 0.644 & $3.46 \times 10^{-6}$ & 0 & 0.38 & $3 / 3$ & 0.03 & - \\
\hline & 2 & rs11682595 & SOCS5 ( 3 ' region) & $\mathrm{T} / \mathrm{G}$ & 0.642 & $3.49 \times 10^{-6}$ & 0 & 0.41 & $3 / 3$ & 0.03 & - \\
\hline & 2 & rs 11125090 & SOCS5 ( 3 ' region) & $\mathrm{A} / \mathrm{G}$ & 0.641 & $3.58 \times 10^{-6}$ & 0 & 0.42 & $3 / 2$ & 0.03 & - \\
\hline & 4 & rs10019008 & BST1 (3' region) & $\mathrm{C} / \mathrm{T}$ & 0.288 & $4.99 \times 10^{-6}$ & 53 & 0.12 & $3 / 0$ & 0.80 & - \\
\hline & 4 & rs 11947310 & BST1 (3' region) & $\mathrm{A} / \mathrm{C}$ & 0.289 & $5.21 \times 10^{-6}$ & 53 & 0.12 & $3 / 3$ & 0.80 & - \\
\hline & 4 & rs10018756 & BST1 (3' region) & $\mathrm{A} / \mathrm{T}$ & 0.275 & $7.71 \times 10^{-6}$ & 48 & 0.15 & $3 / 3$ & 0.77 & - \\
\hline \multirow[t]{9}{*}{ Candidate SNPs } & 15 & rs 1051730 & CHRNA3 (exon, Tyr215Tyr) & $\mathrm{G} / \mathrm{A}$ & 0.010 & 0.851 & 32 & 0.23 & $3 / 0$ & 0.59 & No \\
\hline & 15 & rs16969968 & CHRNA5 (exon, Asp398Asn) & $\mathrm{G} / \mathrm{A}$ & 0.009 & 0.863 & 30 & 0.24 & $3 / 2$ & 0.59 & No \\
\hline & 15 & rs8034191 & AGPHD1 (intron) & $\mathrm{T} / \mathrm{C}$ & 0.006 & 0.914 & 5 & 0.35 & $3 / 0$ & 0.59 & No \\
\hline & 19 & rs7937 & $R A B 4 B$ (3' UTR) & $\mathrm{T} / \mathrm{C}$ & 0.027 & 0.590 & 0 & 0.37 & $3 / 0$ & 0.60 & Yes \\
\hline & 19 & rs1801272 & CYP2A6 (exon, Leu160His) & $\mathrm{A} / \mathrm{T}$ & 0.362 & 0.063 & 0 & 1.00 & $3 / 3$ & 0.96 & Yes \\
\hline & 19 & rs4105144 & CYP2A6 (5' region) & $\mathrm{C} / \mathrm{T}$ & 0.069 & 0.217 & 0 & 0.55 & $3 / 3$ & 0.73 & Yes \\
\hline & 19 & rs7260329 & CYP2B6 (intron) & $\mathrm{G} / \mathrm{A}$ & 0.005 & 0.922 & 0 & 0.76 & $3 / 0$ & 0.68 & Yes \\
\hline & 19 & rs7251570 & CYP2A6 (3' region) & $\mathrm{G} / \mathrm{A}$ & 0.105 & 0.052 & 0 & 0.87 & $3 / 3$ & 0.71 & Yes \\
\hline & 19 & rs12461383 & CYP2A7 (3' region) & $\mathrm{G} / \mathrm{C}$ & 0.143 & 0.008 & 0 & 0.62 & $3 / 3$ & 0.60 & Yes \\
\hline
\end{tabular}

Analyses were adjusted for sex, age, \% of predicted forced expiratory volume in $1 \mathrm{~s}\left(\mathrm{FEV}_{1}\right)$ and principal components for genetic ancestry

$P$ values $<0.05$ are depicted in bold.

$\mathrm{N} / \mathrm{N}_{\text {imp, }}$ number of studies contributing to the meta-analysis/number of studies in which SNP was imputed; $I^{2}$, heterogeneity index; 0 stat., $p$ value for 0 statistic; $p$, $p$ value from the fixed effect meta-analysis; Freq., effect allele frequency in 3441 patients with at least one non-missing phenotype from four cohorts studied; Chr., chromosome; $B$, regression coefficient; UTR, untranslated region; CHRNA3/CHRNA5, cholinergic receptors, nicotinic, alpha $3 / 5 ;$ CYP2A6, cytochrome P450, family 2, subfamily A, polypeptide 6 . 
COPD-specific (eg, reporting lifetime average CPD which may be influenced by severity of disease) characteristics.

Analysis of current CPD, which was much less powered than lifetime CPD because of a lower number of patients, was still able to detect some evidence of association with markers near CYP2A6, yet not for those located in the CHRNA3/CHRNA5 region. CYP2A6 is an enzyme primarily responsible for conversion of nicotine to cotinine in the liver, and rs1801272 (Leu160His) codes for the CYP2A6*2 allele, which inactivates the enzyme. ${ }^{41}$ This SNP showed the largest effect size on both current and lifetime average CPD among all analysed candidate SNPs in the region. Leu160His is in $L D\left(D^{\prime}=1.0\right)$ with other SNPs that were replicated in the CYP2A6 locus. This agrees with previous GWAS and suggests that the rs1801272 SNP may be a true causative variant, while the other associations observed may be due to partial tagging by this SNP. ${ }^{8}$ Importantly, we show that the genotyped proxy SNPs in the CYP2A6 locus confirmed our analysis on imputed SNPs with respect to lifetime average CPD. The lack of convincing association for the proxy SNP rs7251418 with current CPD may be explained by the relatively smaller sample size in this analysis, and incomplete LD between the target and the proxy SNPs. Previous GWAS suggested that other genes may be associated with CPD in the $19 q 13$ region, yet we observed no nominally significant associations for EGLN2, RAB4B and CY2B6.

Analysis of smoking cessation did not reveal any loci associated below the suggestive significance level, and it showed that the previously reported ${ }^{10}$ association between rs3025343 in the $D B H$ locus can be replicated in patients with COPD with a nominal significance threshold. $D B H$ is a plausible candidate gene for smoking cessation because it participates in the metabolism of dopamine. This neurotransmitter is released from neurons in response to nicotine, ${ }^{3}$ and is an important mediator of addiction behaviours such as smoking. The rs3025343 SNP that we extracted showed a substantial heterogeneity in this effect, which may reflect the between-study differences in factors such as use of nicotine replacement therapy or socioeconomic status. Interestingly, the best proxy SNP rs3025316 (genotyped in all cohorts) showed a more pronounced effect with a somewhat smaller heterogeneity index compared with the rs3025343.

Our study possesses several limitations, and some of them are typical for many GWAS. For example, the size of the current study may have been too small to detect associations at a genome-wide significance level. Phenotypes studied are genetically complex and are likely determined by many genes of modest effects, which makes them difficult to detect with genome-wide significance for the currently studied sample size. It is worth noting that the much larger Tobacco and Genetics consortium did not identify any genome-wide significant associations for age at smoking initiation in a meta-analysis encompassing over 20000 subjects. ${ }^{10}$ This emphasises the need for even larger studies to study smoking behaviours in order to detect variants with presumably low effect sizes. Despite the modest effect sizes of the genetic variants implicated by GWAS, key biological pathways may be identified using such approaches. Second, the genotype imputation accuracy could have had an impact on our results. Many top SNPs from the analyses of age at smoking initiation were imputed in all four cohorts; however, the association peaks of these regions also contained SNPs genotyped in the majority (or even all) of the cohorts, which likely makes these findings more reliable. Given the fact that different, and not fully overlapping, genotyping chips were used, this imputation was crucial to obtain a comprehensive overview of many genetic associations. In our study, this is of special importance for the non-synonymous SNP rs1801272 in CYP2A6, which had to be imputed in all cohorts and has no known proxy SNPs. Assuming that the association of this SNP with CPD is a true positive and possibly causal, imputation was the only one way to detect it. Lastly, we must acknowledge that COPD diagnosis has a significant impact on smoking behaviours studied, and especially on current CPD and smoking cessation. We took into account the severity of COPD, reflected in the level of lung function, as a potential confounder when analysing these two phenotypes. However, we hypothesise that additional factors such as frequency of exacerbations may also affect smoking behaviours in the patients with COPD who were studied here. Additionally, it is plausible that social factors, such as smoking trends changing over time, are important environmental determinants of smoking initiation and intensity, and they might have potentially confounded the genetic associations found.

In summary we identified two candidate loci associated with age at smoking initiation in patients with COPD. We showed that variation in the CHRNA3/CHRNA5 locus on chromosome $15 q 25$ locus and the CYP2A6 locus on chromosome 19q13 were associated with lifetime average CPD among patients with COPD. The latter gene may play a significant role in the current smoking intensity among patients with COPD. Future studies in larger populations will be required to determine the overlap between genetic determinants of smoking behaviour in the general population and in patients with COPD.

\section{Author affiliations}

${ }^{1}$ Channing Laboratory, Brigham and Women's Hospital and Harvard Medical School, Boston, Massachusetts, USA

${ }^{2}$ Division of Pulmonary and Critical Care Medicine, Department of Medicine, Brigham and Women's Hospital and Harvard Medical School, Boston, Massachusetts, USA ${ }^{3}$ Department of Thoracic Medicine, Haukeland University Hospital and Institute of Medicine, University of Bergen, Bergen, Norway

${ }^{4}$ Cambridge Institute for Medical Research, University of Cambridge, Cambridge, UK ${ }^{5}$ GlaxoSmithKline Research and Development, Research Triangle Park, North Carolina, USA

${ }^{6}$ GlaxoSmithKline Research and Development, King of Prussia, Pennsylvania, USA ${ }^{7}$ Department of Pulmonary and Critical Care Medicine, University of Nebraska Medical Center, Omaha, Nebraska, USA

${ }^{8}$ Johns Hopkins School of Public Health, Baltimore, Maryland, USA

${ }^{9}$ Department of Epidemiology, Colorado School of Public Health, University of Colorado Denver, Aurora, Colorado, USA

${ }^{10}$ Department of Medicine, National Jewish Health, Denver, Colorado, USA

Acknowledgements ECLIPSE Steering Committee: Harvey Coxson (Canada), Lisa Edwards (GlaxoSmithKline, USA), Katharine Knobil (Co-chair, GlaxoSmithKline, UK), David Lomas (UK), William MacNee (UK), Edwin Silverman (USA), Ruth Tal-Singer (GlaxoSmithKline, USA), Jørgen Vestbo (Co-chair, Denmark), Julie Yates (GlaxoSmithKline, USA).

ECLIPSE Scientific Committee: Alvar Agusti (Spain), Peter Calverley (UK), Bartolome Celli (USA), Courtney Crim (GlaxoSmithKline, USA), Bruce Miller (GlaxoSmithKline, UK), William MacNee (Chair, UK), Stephen Rennard (USA), Ruth Tal-Singer (GlaxoSmithKline, USA), Emiel Wouters (The Netherlands), Julie Yates (GlaxoSmithKline, USA).

ECLIPSE Investigators: Bulgaria: Yavor Ivanov, Pleven; Kosta Kostov, Sofia. Canada: Jean Bourbeau, Montreal, Que; Mark Fitzgerald, Vancouver, BC; Paul Hernandez, Halifax, NS; Kieran Killian, Hamilton, On; Robert Levy, Vancouver, BC; Francois Maltais, Montreal, Que; Denis O’Donnell, Kingston, On. Czech Republic: Jan Krepelka, Praha. Denmark: Jørgen Vestbo, Hvidovre. The Netherlands: Emie Wouters, Horn-Maastricht. New Zealand: Dean Quinn, Wellington. Norway: Per Bakke, Bergen. Slovenia: Mitja Kosnik, Golnik. Spain: Alvar Agusti, Jaume Sauleda, Palma de Mallorca. Ukraine: Yuri Feschenko, Kiev; Vladamir Gavrisyuk, Kiev; Lyudmila Yashina, Kiev; Nadezhda Monogarova, Donetsk. United Kingdom: Peter Calverley, Liverpool; David Lomas, Cambridge; William MacNee, Edinburgh; David Singh, Manchester; Jadwiga Wedzicha, London. United States of America: Antonio Anzueto, San Antonio, Texas; Sidney Braman, Providence, Rhode Island; Richard Casaburi, Torrance, California; Bart Celli, Boston, Massachusetts; Glenn Giessel, Richmond, Virginia; Mark Gotfried, Phoenix, Arizona; Gary Greenwald, Rancho Mirage, California; Nicola Hanania, Houston, Texas; Don Mahler, Lebanon, New 
Hampshire; Barry Make, Denver, Colorado; Stephen Rennard, Omaha, Nebraska; Carolyn Rochester, New Haven, Connecticut; Paul Scanlon, Rochester, Minnesota; Dan Schuller, Omaha, Nebraska; Frank Sciurba, Pittsburgh, Pennsylvania; Amir Sharafkhaneh, Houston, Texas; Thomas Siler, St. Charles, Missouri; Edwin Silverman, Boston, Massachusetts; Adam Wanner, Miami, Florida; Robert Wise, Baltimore, Maryland; Richard ZuWallack, Hartford, Connecticut. We acknowledge the co-investigators in the NETT Genetics Ancillary Study including Joshua Benditt, Gerard Criner, Malcolm DeCamp, Philip Diaz, Mark Ginsburg, Larry Kaiser, Marcia Katz, Mark Krasna, Neil Maclntyre, Barry Make, Rob McKenna, Fernando Martinez, Zab Mosenifar, John Reilly, Andrew Ries, Paul Scanlon, Frank Sciurba, and James Utz.

COPDGene Investigators

The members of the COPDGene study group as of June 2010: Ann Arbour VA: Jeffrey Curtis, MD (PI), Ella Kazerooni, MD (RAD)

Baylor College of Medicine, Houston, Texas: Nicola Hanania, MD, MS (PI), Philip Alapat, MD, Venkata Bandi, MD, Kalpalatha Guntupalli, MD, Elizabeth Guy, MD, Antara Mallampalli, MD, Charles Trinh, MD (RAD), Mustafa Atik, MD

Brigham and Women's Hospital, Boston, Massachusetts: Dawn DeMeo, MD, MPH (Co-PI), Craig Hersh, MD, MPH (Co-PI), George Washko, MD, Francine Jacobson, MD, MPH (RAD)

Columbia University, New York, New York: R. Graham Barr, MD, DrPH (PI), Byron Thomashow, MD, John Austin, MD (RAD)

Duke University Medical Center, Durham, North Carolina: Neil Maclntyre, Jr., MD (PI), Lacey Washington, MD (RAD), H Page McAdams, MD (RAD)

Fallon Clinic, Worcester, Massachusetts: Richard Rosiello, MD (PI), Timothy Bresnahan, MD (RAD)

Health Partners Research Foundation, Minneapolis, Minnesota: Charlene McEvoy, MD, MPH (PI), Joseph Tashijian, MD (RAD)

Johns Hopkins University, Baltimore, Maryland: Robert Wise, MD (PI), Nadia Hansel, MD, MPH, Robert Brown, MD (RAD), Gregory Diette, MD

Los Angeles Biomedical Research Institute at Harbour UCLA Medical Center, Los Angeles, California: Richard Casaburi, MD (PI), Janos Porszasz, MD, PhD, Hans Fischer, MD, PhD (RAD), Matt Budoff, MD

Michael E. DeBakey VAMC, Houston, Texas: Amir Sharafkhaneh, MD (PI), Charles Trinh, MD (RAD), Hirani Kamal, MD, Roham Darvishi, MD

Minneapolis VA: Dennis Niewoehner, MD (PI), Tadashi Allen, MD (RAD), Quentin Anderson, MD (RAD), Kathryn Rice, MD

Morehouse School of Medicine, Atlanta, Georgia: Marilyn Foreman, MD, MS (PI), Gloria Westney, MD, MS, Eugene Berkowitz, MD, PhD (RAD)

National Jewish Health, Denver, Colorado: Russell Bowler, MD, PhD (PI), Adam Friedlander, MD, David Lynch, MB (RAD), Joyce Schroeder, MD (RAD), John Newell, Jr., MD (RAD)

Temple University, Philadelphia, Pennsylvania: Gerard Criner, MD (PI), Victor Kim, MD, Nathaniel Marchetti, DO, Aditi Satti, MD, A. James Mamary, MD, Robert Steiner, MD (RAD), Chandra Dass, MD (RAD)

University of Alabama, Birmingham, Alabama: William Bailey, MD (PI), Mark Dransfield, MD (Co-PI), Hrudaya Nath, MD (RAD)

University of California, San Diego, California: Joe Ramsdell, MD (PI), Paul Friedman, MD (RAD)

University of lowa, lowa City, lowa: Geoffrey McLennan, MD, PhD (PI), Edwin JR van Beek, MD, PhD (RAD), Brad Thompson, MD (RAD), Dwight Look, MD University of Michigan, Ann Arbor, Michigan: Fernando Martinez, MD (PI), MeiLan Han, MD, Ella Kazerooni, MD (RAD)

University of Minnesota, Minneapolis, Minnesota: Christine Wendt, MD (PI), Tadashi Allen, MD (RAD)

University of Pittsburgh, Pittsburgh, Pennsylvania: Frank Sciurba, MD (PI), Joel Weissfeld, MD, MPH, Carl Fuhrman, MD (RAD), Jessica Bon, MD

University of Texas Health Science Center at San Antonio, San Antonio, Texas: Antonio Anzueto, MD (PI). Sandra Adams, MD, Carlos Orozco, MD, Mario Ruiz, MD (RAD)

Administrative Core: James Crapo, MD (PI), Edwin Silverman, MD, PhD (PI), Barry Make, MD, Elizabeth Regan, MD, Sarah Moyle, MS, Douglas Stinson

Genetic Analysis Core: Terri Beaty, PhD, Barbara Klanderman, PhD, Nan Laird, PhD, Christoph Lange, PhD, Michael Cho, MD, Stephanie Santorico, PhD, John Hokanson, MPH, PhD, Dawn DeMeo, MD, MPH, Nadia Hansel, MD, MPH, Craig Hersh, MD, MPH, Jacqueline Hetmanski, MS, Tanda Murray

Imaging Core: David Lynch, MB, Joyce Schroeder, MD, John Newell, Jr., MD, John Reilly, MD, Harvey Coxson, PhD, Philip Judy, PhD, Eric Hoffman, PhD, George Washko, MD, Raul San Jose Estepar, PhD, James Ross, MSc, Rebecca Leek, Jordan Zach, Alex Kluiber, Jered Sieren, Heather Baumhauer, Verity McArthur, Dzimitry Kazlouski, Andrew Allen, Tanya Mann, Anastasia Rodionova PFT QA Core, LDS Hospital, Salt Lake City, UT: Robert Jensen, PhD Biological Repository, Johns Hopkins University, Baltimore, Maryland: Homayoon Farzadegan, PhD, Stacey Meyerer, Shivam Chandan, Samantha Bragan Data Coordinating Center and Biostatistics, National Jewish Health, Denver, Colorado: James Murphy, PhD, Douglas Everett, PhD, Carla Wilson, MS, Ruthie Knowles, Amber Powell, Joe Piccoli, Maura Robinson, Margaret Forbes, Martina Wamboldt
Epidemiology Core, University of Colorado School of Public Health, Denver, Colorado: John Hokanson, MPH, PhD, Marci Sontag, PhD, Jennifer Black-Shinn, MPH, Gregory Kinney, MPH

Funding This work was supported by US National Institutes of Health (NIH) grants R01 HL075478, R01 HL084323, P01 HL083069, U01 HL089856 (Silverman), K12HL089990 (Cho), and U01 HL089897 (Crapo). The National Emphysema Treatment Trial was supported by the National Heart, Lung, and Blood Institute contracts (N01HR76101, N01HR76102, N01HR76103, N01HR76104, N01HR76105, N01HR76106, N01HR76107, N01HR76108, N01HR76109, N01HR76110, N01HR76111, N01HR76112, N01HR76113, N01HR76114, N01HR76115, N01HR76116,

N01HR76118, N01HR76119), the Centers for Medicare and Medicaid Services, and the Agency for Healthcare Research and Quality. The Norway cohort and the ECLIPSE study (http://www.Clinicaltrials.gov identifier NCT00292552; GSK Code SC0104960) are funded by GlaxoSmithKline. The COPDGene project was supported by Award Number U01HL089897 and Award Number U01HL089856 from the National Heart, Lung, and Blood Institute. The content is solely the responsibility of the authors and does not necessarily represent the official views of the National Heart, Lung, and Blood Institute or the National Institutes of Health. The COPDGene project is also supported by the COPD Foundation through contributions made to an Industry Advisory Board comprised of AstraZeneca, Pfizer, Boehringer Ingelheim, Novartis and Sepracor. M. Siedlinski is a recipient of a post-doctoral fellowship from the Niels Stensen Foundation.

Competing interests No competing interests: $\mathrm{MS}, \mathrm{AG}$, GlaxoSmithKline employee: WA, XK, NIH grant: JEH, THB, EKS, JDC, GlaxoSmithKline grant: EKS, DAL, PB, COPD Foundation grant: EKS, JDC, GlaxoSmithKline consulting fee or honorarium and support for travel to meetings for the study or other purposes: EKS, DAL, COPD Foundation support for travel to meetings for the study or other purposes: EKS, JDC, AstraZeneca and GlaxoSmithKline-payment for lectures including service on speakers bureaus and consultancy (outside the submitted work): EKS, PB, Pfizer-payment for lectures including service on speakers bureaus and consultancy (outside the submitted work): PB, GlaxoSmithKline-board membership, consultancy, payment for lectures including service on speakers bureaus and consultancy (outside the submitted work): DAL, Boehringer Ingelheim consultancy (outside the submitted work): DAL, GlaxoSmithKline fees for participation in review activities such as data monitoring boards, statistical analysis, end point committees, and the like: DAL, Consulting fee or honorarium from AstraZeneca, Novartis, Otsuka: SIR, Grant from AstraZeneca, Biomarck, Centocor, Mpex, Nabi, Novartis, Otsuka: SIR, Almirall, Novartis, Nycomed, Pfizer board membership (outside the submitted work): SIR, Almirall, AstraZeneca, Boehringer Ingelheim, California Allergy Society, Creative Educational Concept, France Foundation, GlaxoSmithKline, Information TV, Network for Continuing Education, Novartis, Nycomed, Pfizer-travel/accommodations expenses covered or reimbursed (outside the submitted work): SIR, Able Associates, Adelphi Research, APT Pharma/Britnall, Aradigm, AstraZeneca, Boehringer Ingelheim, Chiesi, Common Health, Consult Complete, COPDForum, Data Monitor, Decision Resource, Defined Health, Dey, Dunn Group, Easton Associates, Equinox, Gerson,

GlaxoSmithKline, Infomed, KOL Connection, M. Pankove, MedaCorp, MDRx Financial Mpex, Oriel Therapeutics, Otsuka, Pennside, PharmaVentures, Pharmaxis, Price Waterhouse, Propagate, Pulmatrix, Reckner Associates, Recruiting Resources, Roche, Schlesinger Medical, Scimed, Sudler and Hennessey, TargeGen, Theravance, UBC, Uptake Medical, VantagePoint Mangement-consultancy (outside the submitted work): SIR.

Ethics approval Partners Human Research Committee and IRBs at each clinical center.

Contributors funding WA, JDC, EKS; concept and design: MS, EKS; data collection PB, AG, DAL, WA, SIR, JDC, EKS; data analysis: MS, MHC, EKS; statistical support: MS, MHC, XK, THB, JEH, EKS; manuscript writing/editing: all authors.

Provenance and peer review Not commissioned; externally peer reviewed.

\section{REFERENCES}

1. Vink JM, Posthuma D, Neale MC, et al. Genome-wide linkage scan to identify loci for age at first cigarette in Dutch sibling pairs. Behav Genet 2006:36:100-11.

2. Li MD, Cheng R, Ma JZ, et al. A meta-analysis of estimated genetic and environmental effects on smoking behavior in male and female adult twins. Addiction 2003:98:23-31.

3. Batra V, Patkar AA, Berrettini WH, et al. The genetic determinants of smoking. Chest 2003;123:1730-9.

4. Schnoll RA, Johnson TA, Lerman C. Genetics and smoking behavior. Curr Psychiatry Rep 2007:9:349-57.

5. Han S, Gelernter J, Luo X, et al. Meta-analysis of 15 genome-wide linkage scans of smoking behavior. Biol Psychiatry 2010;67:12-19.

6. Caporaso N, Gu F, Chatterjee N, et al. Genome-wide and candidate gene association study of cigarette smoking behaviors. PLoS One 2009:4:e4653.

7. Liu YZ, Pei YF, Guo YF, et al. Genome-wide association analyses suggested a nove mechanism for smoking behavior regulated by IL15. Mol Psychiatry 2009;14:668-80.

8. Thorgeirsson TE, Gudbjartsson DF, Surakka I, et al. Sequence variants at CHRNB3CHRNA6 and CYP2A6 affect smoking behavior. Nat Genet 2010;42:448-53. 
9. Liu JZ, Tozzi F, Waterworth DM, et al. Meta-analysis and imputation refines the association of 15q25 with smoking quantity. Nat Genet 2010;42:436-40.

10. Tobacco and Genetics Consortium. Genome-wide meta-analyses identify multiple loci associated with smoking behavior. Nat Genet 2010;42:441-7.

11. Thorgeirsson TE, Geller F, Sulem P, et al. A variant associated with nicotine dependence, lung cancer and peripheral arterial disease. Nature 2008;452:638-42.

12. Pillai SG, Ge D, Zhu G, et al. A genome-wide association study in chronic obstructive pulmonary disease (COPD): identification of two major susceptibility loci. PLoS Genet 2009;5:e1000421.

13. Godtfredsen NS, Lam TH, Hansel TT, et al. COPD-related morbidity and mortality after smoking cessation: status of the evidence. Eur Respir J 2008;32:844-53.

14. Andreas S, Hering T, Muhlig S, et al. Smoking cessation in chronic obstructive pulmonary disease: an effective medical intervention. Dtsch Arztebl Int 2009:106:276-82.

15. Pauwels RA, Rabe KF. Burden and clinical features of chronic obstructive pulmonary disease (COPD). Lancet 2004;364:613-20.

16. Kanner $\mathbf{R E}$, Connett JE, Williams DE, et al. Effects of randomized assignment to a smoking cessation intervention and changes in smoking habits on respiratory symptoms in smokers with early chronic obstructive pulmonary disease: the Lung Health Study. Am J Med 1999;106:410-16.

17. Hu MC, Davies M, Kandel DB. Epidemiology and correlates of daily smoking and nicotine dependence among young adults in the United States. Am J Public Health 2006;96:299-308.

18. Fishman A, Martinez F, Naunheim $\mathrm{K}$, et al. A randomized trial comparing lungvolume-reduction surgery with medical therapy for severe emphysema. $N$ Engl J Med 2003;348:2059-73.

19. Vestbo J, Anderson W, Coxson HO, et al. Evaluation of COPD Longitudinally to Identify Predictive Surrogate End-points (ECLIPSE). Eur Respir J 2008;31:869-73.

20. Zhu G, Warren L, Aponte J, et al. The SERPINE2 gene is associated with chronic obstructive pulmonary disease in two large populations. Am J Respir Crit Care Med 2007; 176:167-73

21. Regan EA, Hokanson JE, Murphy JR, et al. Genetic epidemiology of COPD (COPDGene) study design. COPD 2010;7:32-43.

22. Ferris BG. Epidemiology Standardization Project (American Thoracic Society). Am Rev Respir Dis 1978;118:1-120.

23. Cho MH, Boutaoui N, Klanderman BJ, et al. Variants in FAM13A are associated with chronic obstructive pulmonary disease. Nat Genet 2010;42:200-2.

24. The International HapMap Consortium. The international HapMap project. Nature 2003;426:789-96.
25. Durbin RM, Abecasis GR, Altshuler DL et al. A map of human genome variation from population-scale sequencing. Nature 2010;467:1061-73.

26. Saccone NL, Culverhouse RC, Schwantes-An TH, et al. Multiple independent loci a chromosome 15q25.1 affect smoking quantity: a meta-analysis and comparison with lung cancer and COPD. PLoS Genet 2010;6:e1001053.

27. Venables WN, Ripley BD. Modern applied statistics with S. 4th edn. New York: Springer, 2002

28. Dudbridge $\mathbf{F}$, Gusnanto A. Estimation of significance thresholds for genomewide association scans. Genet Epidemiol 2008:32:227-34.

29. Aulchenko YS, Ripke S, Isaacs A, et al. GenABEL: an $R$ library for genome-wide association analysis. Bioinformatics 2007;23:1294-6.

30. R Development Core Team. R: A language and environment for statistical computing. Vienna, Austria: R Foundation for Statistical Computing, 2010. http://www.R-project.org/.

31. Li Y, Willer C, Sanna S, et al. Genotype imputation. Annu Rev Genomics Hum Gene 2009;10:387-406.

32. Price AL, Patterson NJ, Plenge RM, et al. Principal components analysis corrects for stratification in genome-wide association studies. Nat Genet 2006;38:904-9.

33. Purcell S, Neale B, Todd-Brown K, et al. PLINK: a tool set for whole-genome association and population-based linkage analyses. Am J Hum Genet 2007;81:559-75

34. Purcell S. PLINK (Version 1.0.7). http://pngu.mgh.harvard.edu/ purcell/plink/.

35. Johnson AD, Handsaker RE, Pulit SL, et al. SNAP: a web-based tool for identification and annotation of proxy SNPs using HapMap. Bioinformatics 2008;24:2938-9.

36. Pruim RJ, Welch RP, Sanna S, et al. LocusZoom: regional visualization of genomewide association scan results. Bioinformatics 2010;26:2336-7.

37. Rapley EA, Turnbull C, Al Olama AA, et al. A genome-wide association study of testicular germ cell tumor. Nat Genet 2009;41:807-10.

38. Soranzo N, Spector TD, Mangino M, et al. A genome-wide meta-analysis identifies 22 loci associated with eight hematological parameters in the HaemGen consortium. Nat Genet 2009;41:1182-90.

39. Weiss RB, Baker TB, Cannon DS, et al. A candidate gene approach identifies the CHRNA5-A3-B4 region as a risk factor for age-dependent nicotine addiction. PLoS Genet 2008;4:e1000125

40. Johnson E0, Chen LS, Breslau N, et al. Peer smoking and the nicotinic receptor genes: an examination of genetic and environmental risks for nicotine dependence. Addiction 2010;105:2014-22.

41. Ray R, Tyndale RF, Lerman C. Nicotine dependence pharmacogenetics: role of genetic variation in nicotine-metabolizing enzymes. J Neurogenet 2009;23:252-61. 